J. Dairy Sci. 92:2485-2501

doi:10.3168/jds.2008-1910

(c) American Dairy Science Association, 2009.

\title{
Influence of fatty acid chain length and unsaturation on mid-infrared milk analysis ${ }^{1}$
}

\author{
K. E. Kaylegian, ${ }^{*}$ J. M. Lynch, ${ }^{*}$ J. R. Fleming, $†$ and D. M. Barbano*² \\ *Northeast Dairy Foods Research Center, Department of Food Science, Cornell University, Ithaca, NY 14853 \\ †USDA, Agricultural Marketing Service, Southwest Milk Marketing Area, PO Box 110939, Carrollton, TX 75011
}

\begin{abstract}
Our first objective was to optimize center wavelengths and bandwidths for virtual filters used in a Fourier transform mid-infrared (MIR) milk analyzer. Optimization was accomplished by adjusting center wavelengths and bandwidths to minimize the size of intercorrection factors. Once optimized, the virtual filters were defined as follows: fat B sample, $3.508 \mu \mathrm{m}(2,851$ $\left.\mathrm{cm}^{-1}\right)$, and bandwidth of $0.032 \mu \mathrm{m}\left(26 \mathrm{~cm}^{-1}\right)$; fat B reference, $3.556 \mu \mathrm{m}\left(2812 \mathrm{~cm}^{-1}\right)$, and bandwidth of 0.030 $\mu \mathrm{m}\left(24 \mathrm{~cm}^{-1}\right)$; lactose sample, $9.542 \mu \mathrm{m}\left(1,048 \mathrm{~cm}^{-1}\right)$, and bandwidth of $0.092 \mu \mathrm{m}\left(20 \mathrm{~cm}^{-1}\right)$; lactose reference, $7.734 \mu \mathrm{m}\left(1,293 \mathrm{~cm}^{-1}\right)$, and bandwidth of 0.084 $\mu \mathrm{m}\left(14 \mathrm{~cm}^{-1}\right)$; protein sample, $6.489 \mu \mathrm{m}\left(1,541 \mathrm{~cm}^{-1}\right)$, and bandwidth of $0.085 \mu \mathrm{m}\left(20 \mathrm{~cm}^{-1}\right)$; protein reference, $6.707 \mu \mathrm{m}\left(1491 \mathrm{~cm}^{-1}\right)$, and bandwidth of 0.054 $\mu \mathrm{m}\left(12 \mathrm{~cm}^{-1}\right)$; fat A sample, $5.721 \mu \mathrm{m}\left(1,748 \mathrm{~cm}^{-1}\right)$, and bandwidth of $0.052 \mu \mathrm{m}\left(16 \mathrm{~cm}^{-1}\right)$; fat A reference, $5.583 \mu \mathrm{m}\left(1,791 \mathrm{~cm}^{-1}\right)$, and bandwidth of $0.050 \mu \mathrm{m}$ $\left(16 \mathrm{~cm}^{-1}\right)$. The bandwidth and its proximity to areas of intense water absorption had the largest effect on the intercorrection factors. The second objective was to quantify the impact of fatty acid chain length and unsaturation on fat B and fat A MIR measurements. Increasing the chain length increased the difference (i.e., MIR minus reference) between MIR prediction and reference chemistry by $0.0429 \%$ and by $-0.0566 \%$ fat per unit of increase in carbon number per $1 \%$ change in fat, for fat B and fat A, respectively. Increasing the unsaturation decreased the difference (i.e., MIR minus reference) between MIR prediction of fat and chemistry for fat B by $-0.4021 \%$ and increased fat A by $0.0291 \%$ fat per unit of increase in double bonds per $1 \%$ change in fat concentration.
\end{abstract}

Received November 18, 2008.

Accepted January 8, 2009.

${ }^{1}$ Use of names, names of ingredients, and identification of specific models of equipment is for scientific clarity and does not constitute any endorsement of product by authors, Cornell University, or the Northeast Dairy Foods Research Center.

${ }^{2}$ Corresponding author: dmb37@cornell.edu
Key words: infrared, fatty acid composition, interference filter

\section{INTRODUCTION}

\section{Mid-Infrared Milk Analysis}

The first mid-infrared (MIR) milk analyzers measured fat by measuring absorbance of the carbonyl stretch (now called fat A) at $5.73 \mu \mathrm{m}$, protein by the amide II stretch at $6.46 \mu \mathrm{m}$, and lactose by the carbonhydroxyl stretch at $9.6 \mu \mathrm{m}$ (Goulden, 1964). Fat A measurements were sensitive to variations in the fatty acid chain length caused by variations in feeding, and this caused large standard deviations of the difference (SDD) between reference chemistry and instrument predictions (Sjaunja, 1984a,b). A measurement of light absorbance of the carbon-hydrogen stretch at $3.48 \mu \mathrm{m}$ (fat B) was added as a second measurement of fat because this would be able to compensate for the difference in fatty acid chain length (Biggs and McKenna, 1989). The validation performance of the fat $\mathrm{B}$ filter alone $(\mathrm{SDD}=0.028)$ was better than that of the fat $\mathrm{A}$ filter alone $(\mathrm{SDD}=0.038)$, and sometimes a combination of fats A and $\mathrm{B}(\mathrm{SDD}=0.026)$ gave slightly better performance than fat B (Biggs and McKenna, 1989).

The first generation of MIR milk analyzers used optical interference filters, which are made from layers of mineral crystals that are selected to allow transmission of desired wavelengths of light (Stewart, 1970). Generally, 4 sample filters matched with 4 reference filters have been used, but this has varied from one manufacturer to another (Lynch et al., 2006). Reference wavelengths are positioned near the sample wavelengths for each component to account for water displacement caused by variations in the concentration of the other milk components (Biggs et al., 1987) and to reduce the effects of differences in light scattering between sample and reference filters that are used in combination. The interference filters used in MIR milk analyzers are circular disks mounted in a filter wheel that sequentially moves each filter into the light path and allows a band of wavelengths of light to pass through the sample. 
Variations in the transmission characteristics of optical filters among instruments may cause variations in the MIR prediction of milk components from one instrument to the next, as demonstrated by Smith et al. (1995) for the fat A and fat B filters. Variation of optical filter characteristics (i.e., center wavelengths and bandwidths) is the basis for some of the variation of intercorrection factors from one instrument to another of the same model that was reported by Lynch et al. (2006).

The second generation of MIR milk analyzers is the Fourier transform (FT) MIR instruments. In an FT MIR milk analyzer, the full spectrum of light passes through a beam splitter and part of the light beam is passed, via a mirror, through the sample and onto the detector while the other part of the beam is passed, via another mirror, through the sample and onto the detector (Luginbühl and Eyer, 1992; Agnet, 1998). The differences in light intensities at the detector that result from the differences in the path between the 2 beams is used to create an interferogram, which is then converted to an MIR spectrum using FT mathematics (Agnet, 1998). The FT MIR instrument produces a full spectrum, with background water absorbance subtracted, for each sample. The data from this spectrum can be used in different ways for milk analysis. For example, in software provided by some instrument manufacturers, a fixed-filter instrument simulation approach can be used by creating virtual filters. In this case, the center wavelength and bandwidth for each virtual filter is set by the operator and the precalibration and calibration control can be done as described by Lynch et al. (2006). This has an advantage over optical filters because the virtual filters have more consistent characteristics than optical filters and produce very consistent intercorrection factors from one instrument to the next. The selection of center wavelengths and bandwidths of the virtual filters can be based on the wavelengths used for optical filters. The ability to select the exact center wavelength and bandwidth for each virtual filter in an FT MIR instrument provides an opportunity to optimize the virtual filter performance beyond what is possible with optical filters. Therefore, the first objective of this study was to optimize the classical optical filter center wavelengths and bandwidths for use as virtual filters in a fixed-filter calibration approach with an FT MIR milk analyzer.

\section{Influence of Variations in Fat Composition on MIR Milk Analysis}

Variations in the mean fatty acid chain length and unsaturation that occur in milk fat because of the stage of lactation affect the accuracy of MIR milk analysis (Sjaunja, 1984a,b). Protected lipid feeding techniques designed either to change milk fatty acid composition or to increase the energy intake by dairy cows significantly can cause changes in milk composition that are large enough to influence the accuracy of MIR milk testing. This was demonstrated in several studies in which milk from cows fed protected sunflower-soybean supplements (Dunkley et al., 1977; Barbano and Sherbon, 1980), protected tallow (Franke et al., 1977), and whole cottonseed (Franke et al., 1981) had increased average chain lengths of milk fatty acids and resulted in lower fat tests with MIR analysis than with Babcock analysis. Today, herd sizes have increased and more aggressive nutrition management programs are used (e.g., fat supplements to increase energy intake and maximize milk production). Stegeman et al. (1991) reported that increased fatty acid unsaturation resulted in a lower fat test by MIR milk analysis. These feeding strategies may affect fatty acid composition of milk fat. No reports in the literature have quantified the relationship between a change in fatty acid chain length and a change in unsaturation on the change in absorbance of light at the sample and reference wavelengths used for fat B and fat A, or other changes that may take place in the rest of the MIR spectra of milk. The second objective of this study was to separately quantify the influence of variations in fatty acid chain length and unsaturation on absorbance of light at the fat B and fat A sample and reference wavelengths, absorbance of light at other MIR wavelengths, and MIR fat prediction. This knowledge may allow the development of analytical strategies to correct for these variations in fat composition and improve the accuracy of milk testing.

\section{MATERIALS AND METHODS}

\section{Experimental Design}

Optimization of FT MIR Bandwidth and Center Wavelength. The initial center wavelength and bandwidth settings used in the FT MIR milk analyzer in our study were based on those used in the FT120 instrument (Foss Electric, 2002). A systematic approach was used to optimize the bandwidth and the sample and reference center wavelengths for milk analysis. The impact of each incremental change in center wavelength and bandwidth was assessed by calculating new linearity, primary slope, and intercorrection factors that achieved the best agreement between the MIR prediction minus chemistry when plotted as a function of the other components being measured (i.e., protein and lactose). The milk samples used for the optimization process were sets of 14 modified milk calibration samples described previously (Kaylegian et al., 2006). The optimal bandwidths and center wavelengths were those 
that yielded intercorrection factors closest to zero, that yielded the smallest SDD between MIR prediction and chemistry, and that gave excellent repeatability (i.e., $<0.02 \%$ variation on 18 consecutive measurements of the same sample).

Impact of Fatty Acid Chain Length and Unsaturation on MIR Prediction of Fat. Two series of milk emulsions made with pure monoacid triglycerides were used. The first milk emulsion series varied only in mean fatty acid chain length and was made by blending stock emulsions of pure C14:0 and C16:0 monoacid triglycerides and pasteurized skim milk. The 2 stock emulsions were blended to yield individual samples with mean fatty acid chain lengths of 14.0, 15.0, 15.2, $15.4,15.6,15.8$, and 16.0 carbons and a fat content of $1.9 \%$. The second milk emulsion series varied only in the mean unsaturation and was made by blending stock emulsions of pure C18:0 and C18:1 monoacid triglycerides and pasteurized skim milk. These 2 emulsions were blended to yield individual milk emulsions with mean unsaturation of $0,0.3,0.4,0.5,0.6$, and 1.0 carbon-carbon double bonds and a fat content of $1.9 \%$. Both series of emulsions were analyzed for full-spectrum data from 3.3 to $10 \mu \mathrm{m}$ (3,000 to $1,000 \mathrm{~cm}^{-1}$ ) using an FT MIR milk analyzer. The impacts of fatty acid chain length and unsaturation at the fat $\mathrm{B}$ and fat $\mathrm{A}$ wavelengths were determined by using both an FT MIR milk analyzer with optical interference filters and an FT MIR milk analyzer using virtual filters with the optimized center wavelength and bandwidths determined in the first phase of this study. The changes in fat B and fat A readings with a change in fatty acid chain length and unsaturation were determined by using linear regression. The experiment was replicated 3 times.

\section{Milk Emulsion Preparation}

Fat Sources. The fatty acid chain lengths and unsaturation series were formulated by using pure C14:0, C16:0, C18:0, and C18:1 monoacid triglycerides (T-140, T-160, T-180, T-235, respectively; NuChek Prep, Elysian, MN). A single lot of each triglyceride was purchased in sufficient quantity for all 3 replicates and was stored frozen $\left(-13^{\circ} \mathrm{C}\right)$.

Stock Emulsion Production. All of the stock emulsions for a single replicate of the experiment were made on the same day, using the same source of skim milk. Raw skim milk was obtained from the Cornell University Dairy Plant and was centrifuged in 1,350-g batches for $5 \mathrm{~min}$ at 5,000 rpm (approximately 2,560 $\times$ g) using a Sorvall Evolution RC centrifuge with GSA rotor (Kendro Laboratory Products, Newton, CT) to remove residual fat. The centrifuged raw skim milk $(0.09 \%$ fat $)$ was batch pasteurized $(11 \mathrm{~L})$ in a steam kettle (model DN5SP, Groen, Chicago, IL) at $65^{\circ} \mathrm{C}$ for 30 min. The skim milk was cooled in an ice bath and held overnight at $4^{\circ} \mathrm{C}$.

The cold, pasteurized skim milk and the pure monoacid triglycerides were heated to $72^{\circ} \mathrm{C}$ to ensure that the C18:0 triglyceride was fully melted. The blending probe of an Omni Mixer Homogenizer (model 17105, Omni International, Waterbury, CT) was warmed with $72^{\circ} \mathrm{C}$ skim milk by mixing at speed 1.5 for $30 \mathrm{~s}$ immediately before blending the melted triglyceride with the skim milk. The $72^{\circ} \mathrm{C}$ skim milk for each stock emulsion was mixed with the Omni Mixer for $20 \mathrm{~s}$ at speed 1.5, and then the melted fat was added while the skim milk was mixing. The mixture was blended for $20 \mathrm{~s}$ and then used to rinse the container that held the melted triglyceride to ensure a complete transfer. The mixture of skim milk plus triglyceride was blended for an additional $2 \mathrm{~min}$ at speed 1.5. The blended mixture was immediately transferred to a microfluidizing homogenizer (model 110T, Microfluidizer Corp., Newton, MA), that had been warmed using the $72^{\circ} \mathrm{C}$ skim milk and was immediately homogenized at 110 to $124 \mathrm{MPa}$. The purpose of mixing the skim milk plus the fat with the Omni Mixer before homogenization with the microfluidizer was to disperse the fat in the skim milk so the fat would not stick to the sides of the stainless steel containers when it was fed into the homogenizer. The skim milk plus the pure $\mathrm{C} 16: 0$ or $\mathrm{C} 18: 0$ triglycerides were passed through the microfluidizer twice at $72^{\circ} \mathrm{C}$ to obtain a stable emulsion with a uniform and small particle size distribution. The stock emulsions were transferred to glass Erlenmeyer flasks, cooled on ice, and held at $4^{\circ} \mathrm{C}$. The clear glass allowed visual detection of creaming that would indicate an unstable emulsion. No creaming was observed.

Chemical and Physical Analyses of the Stock Emulsions. The fat content of each stock emulsion was determined using a Mojonnier ether extraction (AOAC, 2000; method 989.05, chapter 33.2.26) that was modified to achieve complete extraction of the C16:0 and C18:0 pure monoacid triglycerides. After the third extraction specified in the Mojonnier method, there was a large amount of white, solid triglyceride (that did not dissolve in the ether) located at the interface between the ether layer and the aqueous layer. To recover this fat, 2 additional extractions with a different solvent mixture were performed. For each additional extraction, $2 \mathrm{~mL}$ of $95 \%$ ethyl alcohol was added to the flask and shaken for $15 \mathrm{~s}$. Next, $30 \mathrm{~mL}$ of hexane was added and the flask was shaken for $1 \mathrm{~min}$, followed by centrifuging at $600 \mathrm{rpm}$ for $\geq 30 \mathrm{~s}$ to obtain a clean separation of the aqueous and hexane phases. The hexane phase was decanted into the ether collection pan and the solvent was removed by evaporation. 
The FFA content (expressed as $\mathrm{mEq}$ of $\mathrm{FFA} / \mathrm{kg}$ of milk) of the stock emulsions was determined by using a modified copper soap method (Ma et al., 2003) to ensure that the FFA content of the stock emulsions was low and uniform. Relative fatty acid methyl ester composition of the pure triglycerides was determined in duplicate by using a base-catalyzed transmethylation, followed by separation with capillary GLC and the flame-ionization detection method described by Lynch et al. (2005). The fatty acid analysis of the pure monoacid triglycerides verified that contamination with other fatty acids was $<1 \%$, as claimed by the supplier. Particle size distribution of the fat globules in the stock emulsions was determined by using the laser lightscattering method described by Smith et al. (1995). Particle size was expressed in microns as the particle diameter $[\mathrm{d}(0.9)]$ below which $90 \%$ of the volume of fat was contained.

Preparation of Chain Length and Unsaturation Emulsion Series. The series of milk emulsions that varied only in mean fatty acid chain length was prepared by mixing the $\mathrm{C} 14: 0(\mathrm{MW}=228.38)$ and C16:0 ( $\mathrm{MW}=256.43)$ stock emulsions. The series of milk emulsions that varied only in unsaturation was prepared by mixing the $\mathrm{C} 18: 0(\mathrm{MW}=284.48)$ and C18:1 (MW $=282.48)$ stock emulsions. Formulation of each individual emulsion in the series was calculated based on the weight of fatty acid chains (corrected for the contribution of the glycerol) needed to yield mean chain lengths of $15.0,15.2,15.4,15.6,15.8$, or 16.0 carbons or a mean unsaturation of $0,0.3,0.4,0.5,0.6$, or 1.0 carbon-carbon double bonds per fatty acid. The same pasteurized skim milk that was used to make the stock emulsions was used to dilute individual samples in each emulsion series to obtain a consistent fat content of $1.9 \%$ in all individual emulsions used in this study.

\section{MIR Analysis}

Mid-infrared analyses were performed using a MilkoScan 605 instrument (Foss Electric, Hillerød, Denmark) with optical interference filters as characterized by Smith et al. (1995) and a LactoScope FT infrared (FTIR) instrument (Delta Instruments, Drachten, the Netherlands). The sample and reference center wavelengths and bandwidths were adjustable on the LactoScope FTIR, and it was operated as if it were a fixed-filter instrument. A resolution of $8 \mathrm{~cm}^{-1}$ and 8 scans per sample were used. The LactoScope FTIR instrument was equipped with the FTIRScope and DataScope software from Delta Instruments, and both instruments were equipped with the IR-QC software developed at Cornell University. The IR-QC software automates all precalibration testing (Lynch et al., 2006) and carries out statistical quality assurance diagnostic procedures (e.g., residual plots, intercorrection plots, individual sample leverage calculation, etc.) on calibration data (Kaylegian et al., 2006) and pilot milk checks during routine milk analysis. The sample and reference center wavelengths and bandwidths for fat B, lactose, protein, and fat $\mathrm{A}$ for the optical filters of the MilkoScan 605 instrument and the virtual filters recommend for the Foss FT120 instrument are shown in Table 1. Both instruments were precalibrated (Lynch et al., 2006) and calibrated (Kaylegian et al., 2006) using methods described previously. Precalibration samples were obtained from a USDA Federal Milk Market Laboratory and modified milk calibration samples were produced at Cornell University.

Optimization of FT MIR Bandwidths and Center Wavelengths. The optimization experiment was done with the LactoScope FTIR instrument because the sample and reference wavelengths and bandwidths were adjustable. These parameters were varied systematically to determine the combination that produced intercorrection factors closest to zero. First, the impact of different bandwidths on the size of the intercorrection factors for both sample and reference filters was determined. Bandwidths were varied systematically from 80 to $40 \mathrm{~cm}^{-1}$. Each time the bandwidth was changed, the precalibration mode of the IR-QC software was used to determine the new gain setting needed to return the primary slope of the uncorrected reading back to 1.00 \pm 0.01 (Lynch et al., 2006). The new value for gain (called "scale" in the FTIRScope software) was updated in the method setup section of the FTIRScope software. Next, the calibration mode of the IR-QC software was used to calibrate the instrument using modified milk calibration samples (Kaylegian et al., 2006) to obtain the MIR corrected data for fat, lactose, and protein with the new bandwidth and primary slope settings. The corrected MIR data were used to determine the amount of residual nonlinearity by plotting the residual difference between MIR prediction and reference chemistry. If there was curvature in this residual plot, then the linearity was adjusted in the FTIRScope software (by changing the power setting) and the process of gain adjustment and calibration was repeated until the nonlinearity for each component was eliminated. Once the linearity and primary slope were adjusted, then another set of modified milk calibration samples was analyzed and the residual differences between MIR prediction and reference chemistry were plotted as a function of the concentrations of other components (e.g., fat vs. protein and lactose, protein vs. fat and lactose, and lactose vs. fat and protein). If there was a slope in any of the residual plots, then the appropriate intercorrection factor was adjusted until there was no slope in the 
residual plot. This allowed determination of the change in intercorrection factors with changing bandwidths.

Bandwidths that gave intercorrection factors closest to zero were used in the next experiment to optimize the sample and reference center wavelengths. Optimization of sample and reference wavelengths had to consider both the absorbance spectra of milk and the $0.01 \%$ Triton X-100 in water zeroing solution. In general, areas of the MIR spectra with strong or rapidly changing absorbance caused by water are not useful for MIR milk analysis. The starting sample and reference center wavelengths were selected based on those used in classical optical filter instruments such as the MilkoScan 605. The spectra of milk and water collected from the LactoScope FTIR instrument were examined, and sample and reference wavelengths were selected in the FTIRscope software to create the largest difference in absorbance between each pair of sample and reference wavelengths on milk. Once this was done, the linearity, primary slope, and intercorrection factors were adjusted as described above. Finally, the sample and reference center wavelengths were varied and bandwidths were further decreased to achieve intercorrection factors that were as close to zero as possible. The combination of sample and reference center wavelengths and bandwidths that gave the smallest intercorrection factor were then checked to ensure that the SDD between MIR prediction and reference chemistry was minimized, and that they gave excellent repeatability on multiple analyses of the same sample.

MIR Spectra Analysis of Milk Emulsions. The series of milk emulsions that varied only in chain length and only in unsaturation were analyzed with the LactoScope FTIR instrument using the optimized bandwidths and center wavelength and with the MilkoScan 605 instrument on the same day. All samples were warmed to $72^{\circ} \mathrm{C}$ and then cooled to $41 \pm 1^{\circ} \mathrm{C}$ in a water bath before analysis to ensure that the $\mathrm{C} 16: 0$ or $\mathrm{C} 18: 0$ monoacid triglyceride was fully melted.

The spectrum from 3.3 to $10.0 \mu \mathrm{m}$ (3,000 to 1,000 $\mathrm{cm}^{-1}$ ) was collected for each emulsion by using the FTIRScope software, and uncorrected data were collected simultaneously by using the DataScope software. The saved spectra files (x,y coordinates) were converted to Excel files (Microsoft Inc., Seattle, WA) using the Grams/32 AI software (version 6, Thermo Electron Corp., Somerset, NJ). The spectra were plotted with Excel using the $\mathrm{x}, \mathrm{y}$ graph function and the point-to-point (i.e., not smoothed) line option. These spectra were used to examine the effects of fatty acid chain length and unsaturation at the classical sample and reference wavelengths for fat B and fat $\mathrm{A}$, and on the spectra as a whole. 
MIR Predicted Fat Content. The MilkoScan 605 and the LactoScope FTIR instruments operating in the fixed-filter mode were both used to predict fat chemistry of the 2 emulsion series. The LactoScope instrument used the intercorrection factors established for the optimized center wavelengths and bandwidths. The corrected readings were calculated from the uncorrected readings with the calibration equations described by Lynch et al. (2006). The secondary slope and intercept values of the calibration equations were established for each instrument each day the milk emulsion series were analyzed. The secondary slopes and intercepts were determined by linear regression using the modified milk samples (Kaylegian et al., 2006).

\section{Statistical Analyses}

A regression analysis was performed using the PROC REG function in SAS (version 8e, SAS Inst. Inc., Cary, NC) to determine whether there was a change $(P<$ 0.05) in MIR absorbance (Lactoscope FTIR only) or a corrected reading (LactoScope FTIR and MilkoScan 605) with a change in fatty acid chain length (pure triglyceride series) or unsaturation (pure triglyceride series). The regression analysis for MIR absorbance was conducted individually for fat $\mathrm{B}$ and fat $\mathrm{A}$ at the sample and the reference wavelength (LactoScope FTIR only).

\section{RESULTS AND DISCUSSION}

\section{Optimization of FT MIR Center Wavelengths and Bandwidths for Milk Analysis}

Milk and Water Spectra. Water absorbs light throughout the 2- to $10-\mu \mathrm{m}$ range of the MIR spectrum, but has particularly strong absorbance at around 3 and $6 \mu \mathrm{m}$. Milk is approximately $88 \%$ water and the absorptivities of milk components are low compared with water; thus, the differences between the MIR spectra of water and milk are very small (Figure 1). To measure the differences in fat, lactose, and protein contents among milk samples, the water spectra, obtained by zeroing with a $0.01 \%$ Triton X-100 in water solution, were subtracted from the milk spectra (Figure 2). Triton $\mathrm{X}-100$ is a surfactant used to reduce the occurrence of air bubbles in the cuvette that cause poor repeatability. Triton X-100 does absorb light at the wavelengths used for milk analysis. When the zero of an MIR milk analyzer was set with $0.01 \%$ Triton X-100 in water and then uncorrected readings of a $1 \%$ Triton $\mathrm{X}-100$ in water solution were made, the values were $0.24,0.10,-0.14$, and $-0.06 \%$ for fat $\mathrm{B}$, lactose, protein, and fat A, respectively, for the $1 \%$ Triton X-100

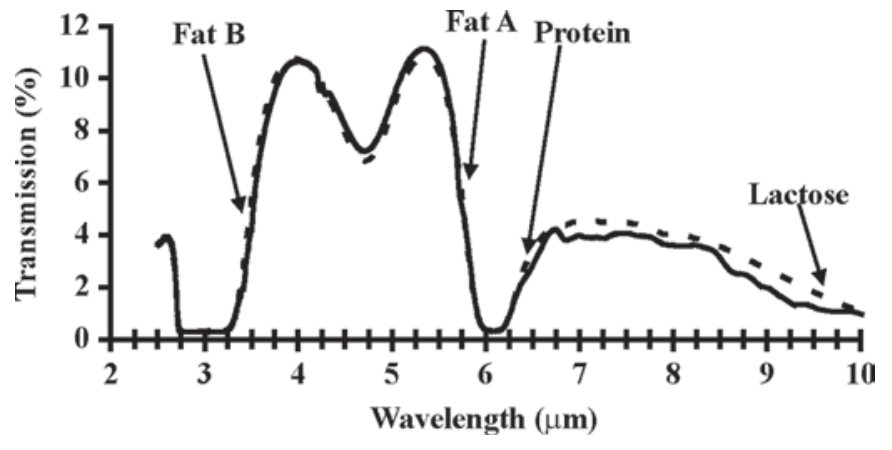

Figure 1. Mid-infrared transmission spectra of water (dashed line) and milk (solid line) with approximate wavelengths of the fat B, fat A, protein, and lactose measurements indicated.

solution. Based on inspection of the spectra for the $1 \%$ Triton X-100 in water solution, when the zero values were positive, the Triton X-100 was absorbing more light at the sample wavelength than at the reference wavelength, and when the values were negative, the absorbance was stronger at the reference wavelength than at the sample wavelength. At a $0.1 \%$ Triton X-100 in water concentration (10-fold higher than desired), there was no detectable impact on the lactose, protein, and fat $\mathrm{A}$ zero readings, but the fat $\mathrm{B}$ zero reading was high by approximately 0.02 to $0.03 \%$ fat. Therefore, it is important to control the concentration of the zeroing solution of Triton X-100 in water. We recommend that a concentration of $0.01 \%$ Triton X-100 in water be used as a zeroing solution for all instruments.

The large water absorption peak near $3 \mu \mathrm{m}$ (Figure 1) was due to the $\mathrm{O}-\mathrm{H}$ asymmetric and symmetric stretches. The water absorption at $3 \mu \mathrm{m}$ overlapped with the asymmetric $(3.418 \mu \mathrm{m})$ and symmetric $(3.509$ $\mu \mathrm{m}) \mathrm{C}-\mathrm{H}$ stretch of the $\mathrm{CH}_{2}$ and $\mathrm{CH}_{3}$ groups of the

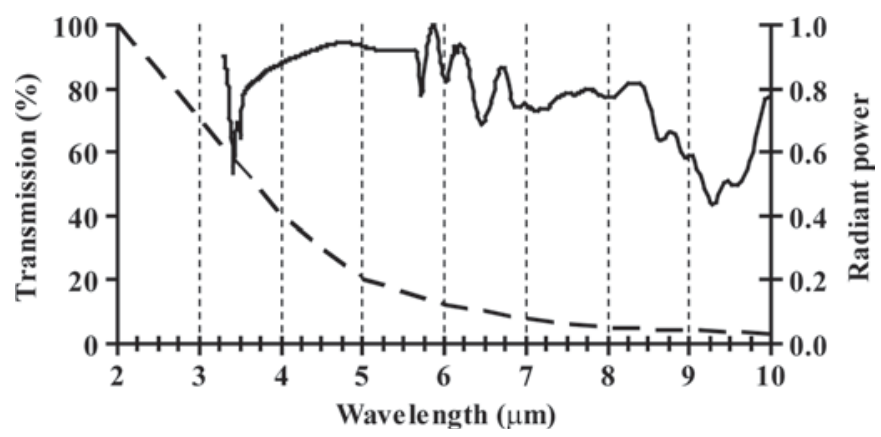

Figure 2. Mid-infrared (MIR) transmission spectra of milk with the water spectra subtracted (solid line) and relative radiant emission power of a blackbody MIR light source (dashed line). Center wavelengths used in the MilkoScan 605 (Foss Electric, Hillerød, Denmark) for sample and reference pairs were 3.48 and $3.60 \mu \mathrm{m}$ for fat B, 5.73 and $5.60 \mu \mathrm{m}$ for fat A, 6.46 and $6.70 \mu \mathrm{m}$ for protein, and 9.61 and 7.70 $\mu \mathrm{m}$ for lactose, respectively. 
triglycerides (Silverstein and Bassler, 1967) in milk that were used for the fat B measurement in fixed-filter MIR milk analysis (Figure 2). The large water absorption peak near $6 \mu \mathrm{m}$ (Figure 1) was due to the $\mathrm{O}-\mathrm{H}$ scissoring and fell between the $\mathrm{C}=\mathrm{O}$ stretch at $5.73 \mu \mathrm{m}$ and the amide II stretch at $6.46 \mu \mathrm{m}$ (Silverstein and Bassler, 1967) that were used for the fat A and protein measurements in fixed-filter MIR milk analysis (Figure 2). The $\mathrm{C}-\mathrm{OH}$ stretch at $9.61 \mu \mathrm{m}$ was used for lactose measurement in the fixed-filter MIR milk analysis (Figure 2). In the areas of intense water absorption (Figure 1), it was not possible to make measurements of small differences because of the absorbance of milk components.

Optical Versus Virtual Filters. In MIR milk analyzers that use optical interference filters [i.e., Foss MilkoScan 104, 255, 300, 605, 4000, Multispec Dairylab (Foss Electric), Delta LactoScope C (Delta Instruments), and Bentley 2000 (Bentley Instruments, Chaska, MN)], all wavelengths of light from the source pass through each optical filter in a timed sequence to select the center wavelength and bandwidth region of the MIR spectrum before the light passes through the sample and then to the detector (Biggs, et al., 1987). The wavelengths used for reference filters can differ from one instrument manufacturer to another (Lynch et al., 2006), and this may cause differences in method performance among instruments from different manufacturers. The light transmission curves of optical filters were not perfectly Gaussian and the center wavelength and bandwidth varied from one filter to the next (Smith et al., 1995). Variation in optical filter characteristics, and therefore center wavelengths and bandwidths, is the cause of some of the variation in intercorrection factors among instruments of the same model reported by Lynch et al. (2006).

An FT MIR milk analyzer can be operated using a fixed-filter approach for milk analysis by selecting bands of wavelengths to create virtual filters that select data from the full spectrum, if the software of the instrument provides access to this information (e.g., Delta LactoScope FTIR and Foss FT120). Virtual filters have an advantage over optical filters because the center wavelength and bandwidth can be set consistently from one instrument to the next. Virtual filters on an FT MIR analyzer differ from optical interference filters because the light transmission intensity is uniform at all wavelengths within the band of wavelengths selected, instead of the near-Gaussian distribution of transmission intensity reported for optical filters by Smith et al. (1995).

One aspect of MIR analysis that does not differ between instruments using optical or virtual filters is the general behavior of the power output of the light source. The output intensity of a blackbody MIR light source at $10 \mu \mathrm{m}$ is only approximately $3 \%$ of the output at 2 $\mu \mathrm{m}$ (Alpert et al., 1970), as shown in Figure 2. Optical filters have smaller bandwidths at shorter wavelengths (e.g., fat B at $3.48 \mu \mathrm{m}$ ) and larger bandwidths at longer wavelengths (e.g., lactose at $9.61 \mu \mathrm{m}$; Table 1 ) to account for the decrease in the power output of the source with increasing wavelengths. Smaller bandwidths were used for the virtual filters of the Foss FT120 instrument compared with the optical filters of the MilkoScan 605 instrument at similar wavelengths (Table 1). Virtual filters do not have the Gaussian transmission characteristics of optical filters; therefore, a narrower band of wavelengths will achieve the same signal intensity at the detector as the wider bandwidth of an optical filter. For both optical and virtual filters, the bandwidth (in $\mu \mathrm{m}$ ) increases as wavelength increases (Table 1) to compensate for the decrease in power output of the light source with increasing wavelength.

Bandwidth Optimization. The goal of the bandwidth experiment was to maintain the initial center filter wavelengths used in the Foss FT120 instrument (Table 1) and change the bandwidths for all sample and reference virtual filters in the LactoScope FTIR instrument to determine the impact of bandwidth on the size of the intercorrection factors. However, when beginning with a bandwidth of $80 \mathrm{~cm}^{-1}$, we found that the position of the center wavelength had to be moved (as compared with the Foss FT120 recommended center wavelength) to avoid too much overlap with areas of intense water absorbance. Therefore, center wavelengths used to determine the impact of systematically changing bandwidth are shown in Table 2. As the bandwidth was decreased simultaneously for the sample and reference wavelengths from a frequency of 80 to $40 \mathrm{~cm}^{-1}$, at a constant center wavelength for each the sample and reference filter pair, the intercorrection factors became closer to zero (Table 2). The primary reason for the decrease in size of the intercorrection factors with decreasing bandwidth was the decrease in overlap of the sample wavelengths with background water absorbance. Thus, in the next experiment on center wavelength optimization, the smallest practical bandwidths (as shown in Table 3) were used.

Center Wavelength Optimization. An expanded view of the milk spectra, with the water spectra subtracted, showing the center wavelengths and bandwidths for the sample and reference pairs for fat B, lactose, protein, and fat $\mathrm{A}$ are shown in Figure $3 \mathrm{a}, 3 \mathrm{~b}, 3 \mathrm{c}$, and $3 \mathrm{~d}$, respectively. The initial center sample wavelength for the fat B measurement with optical filters was 3.48 $\mu \mathrm{m}$ (Table 1 and Figure 3a). In the area of the milk spectra where the fat $\mathrm{B}$ measurement was made, there were 2 areas of light absorption by fat, one at $3.42 \mu \mathrm{m}$, representing asymmetric stretch of the $\mathrm{C}-\mathrm{H}$ bond in 
the $\mathrm{CH}_{2}$ and $\mathrm{CH}_{3}$ groups, and the other at $3.50 \mu \mathrm{m}$, representing the symmetric stretch of the $\mathrm{C}-\mathrm{H}$ bond in the $\mathrm{CH}_{2}$ and $\mathrm{CH}_{3}$ groups (Figure 3a). Although it appeared that the fat $\mathrm{B}$ sample center wavelength should be moved closer to the larger asymmetric $\mathrm{C}-\mathrm{H}$ stretch peak at $3.42 \mu \mathrm{m}$ (Figure $3 \mathrm{a}$ ), that would mean moving closer to an area of very intense and rapidly increasing absorption of MIR light by water (Figure 1). As a result, moving the fat B sample wavelength closer to the asymmetric $\mathrm{C}-\mathrm{H}$ stretch peak would dramatically increase the size of the intercorrection factors (data not shown). When the fat B sample wavelength was moved from 3.480 to $3.508 \mu \mathrm{m}$, which was closer to the asymmetric $\mathrm{C}-\mathrm{H}$ stretch peak (Figure 3a), and the reference center wavelength was moved from 3.597 to $3.556 \mu \mathrm{m}$ (Figure $3 \mathrm{a})$, the size of the intercorrection factors for lactose and protein on fat $\mathrm{B}$ were minimized (Table 3 ).

The initial sample center wavelength used for lactose measurement with optical filters was $9.61 \mu \mathrm{m}$ (Table 1 and Figure $3 \mathrm{~b}$ ). The sample center wavelength was moved from 9.61 to $9.542 \mu \mathrm{m}$ and the reference wavelength was moved from 7.70 to 7.722 (Tables 1 and 3 and Figure $3 \mathrm{~b}$ ). These changes, combined with the smaller bandwidth, increased the difference in absorbance between the sample and reference filters and minimized the size of intercorrection factors for fat B and protein on lactose (Tables 3) compared with the optical filters (Table 1).

The initial sample center wavelength used for protein measurement with optical filters was $6.46 \mu \mathrm{m}$ (Table 1 and Figure 3c) and was adjacent to the area of intense water absorption because of the $\mathrm{O}-\mathrm{H}$ scissoring vibration at $6 \mu \mathrm{m}$ (Figure 1). The use of narrower bandwidths for both the virtual sample and reference filters increased the net difference in absorbance between them (Figure 3c). The sample and reference center wavelengths for protein were moved from the initial values of 6.46 and $6.70 \mu \mathrm{m}$ (Table 1 and Figure 3c) to optimized values of 6.489 and $6.707 \mu \mathrm{m}$ (Table 3 and Figure 3c), respectively, to move them farther away from the water absorption peak. The optimized virtual sample and reference center wavelengths and bandwidths for protein shown in Table 3 also reduced the sensitivity of the protein measurement to variations in sample temperature, which improved repeatability (data not shown).

The initial sample center wavelength used for the fat A measurement was $5.73 \mu \mathrm{m}$ (Table 1 and Figure 3d) and was adjacent to the area of intense water absorption because of the $\mathrm{O}-\mathrm{H}$ scissoring vibration at 6 $\mu \mathrm{m}$ (Figure 1). As was the case for protein, the use of narrower bandwidths for both the virtual sample and reference filters for fat $\mathrm{A}$ increased the net difference in absorbance between the sample and reference

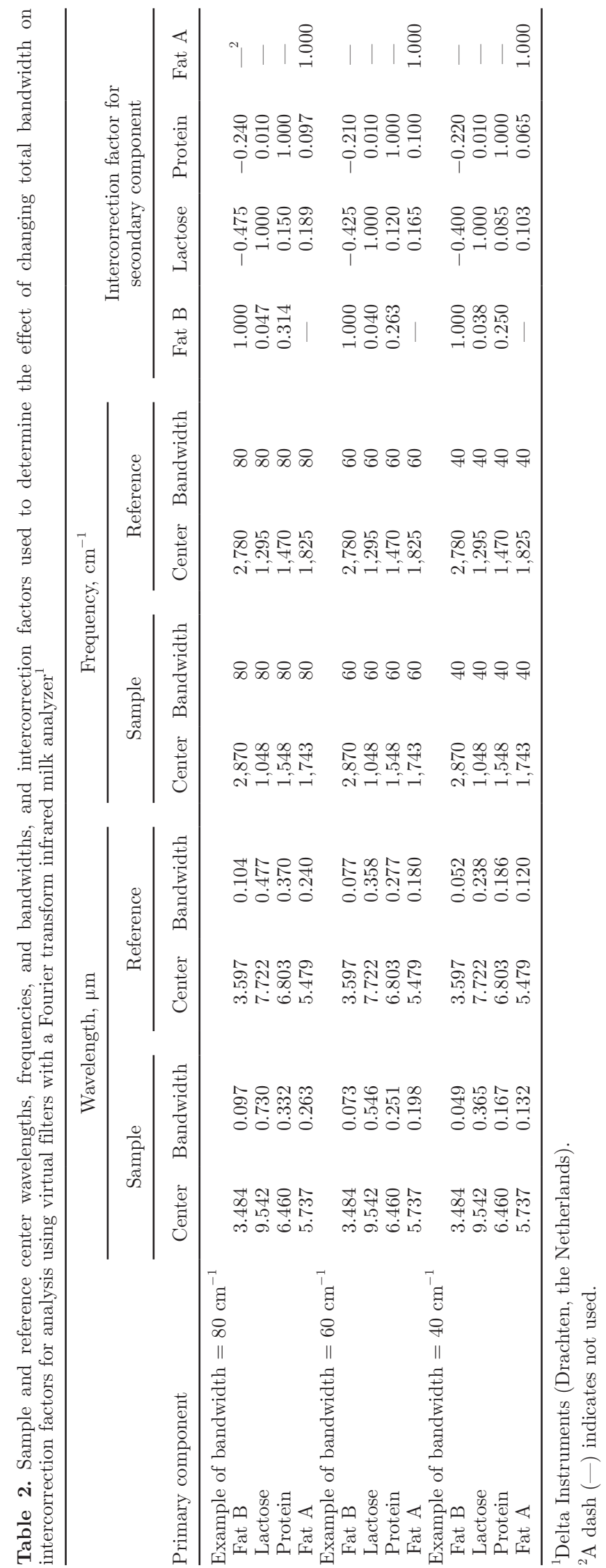


Table 3. Two examples of sample and reference center wavelengths, frequencies, and bandwidths, and intercorrection factors used to determine the effect of changing sample and reference center wavelengths and bandwidths on intercorrection factors, and the optimized virtual filter center wavelengths and bandwidths

\begin{tabular}{|c|c|c|c|c|c|c|c|c|c|c|c|c|}
\hline \multirow[b]{3}{*}{ Primary component } & \multicolumn{4}{|c|}{ Wavelength, $\mu \mathrm{m}$} & \multicolumn{4}{|c|}{ Frequency, $\mathrm{cm}^{-1}$} & \multirow{2}{*}{\multicolumn{4}{|c|}{$\begin{array}{l}\text { Intercorrection factor for } \\
\text { secondary component }\end{array}$}} \\
\hline & \multicolumn{2}{|c|}{ Sample } & \multicolumn{2}{|c|}{ Reference } & \multicolumn{2}{|c|}{ Sample } & \multicolumn{2}{|c|}{ Reference } & & & & \\
\hline & Center & Bandwidth & Center & Bandwidth & Center & Bandwidth & Center & Bandwidth & Fat B & Lactose & Protein & Fat A \\
\hline \multicolumn{13}{|c|}{$\begin{array}{l}\text { Example 1: Impact of a change in fat B sample wavelength } \\
\text { and in sample and reference bandwidths on intercorrection factors }\end{array}$} \\
\hline Fat B & 3.509 & 0.027 & 3.597 & 0.028 & 2,850 & 22 & 2,780 & 22 & 1.000 & -0.198 & -0.093 & $\varkappa^{1}$ \\
\hline Lactose & 9.542 & 0.200 & 7.722 & 0.131 & 1,048 & 22 & 1,295 & 22 & 0.035 & 1.000 & 0.010 & - \\
\hline Protein & 6.566 & 0.069 & 6.729 & 0.073 & 1,523 & 16 & 1,486 & 16 & 0.074 & 0.100 & 1.000 & - \\
\hline Fat A & 5.764 & 0.053 & 5.590 & 0.050 & 1,735 & 16 & 1,789 & 16 & - & 0.078 & 0.058 & 1.000 \\
\hline \multicolumn{13}{|c|}{$\begin{array}{l}\text { Example 2: Impact of a change in fat B reference wavelength } \\
\text { and in sample and reference bandwidths on intercorrection factors }\end{array}$} \\
\hline Fat B & 3.484 & 0.027 & 3.559 & 0.028 & 2,870 & 22 & 2,810 & 22 & 1.000 & -0.383 & -0.200 & - \\
\hline Lactose & 9.542 & 0.200 & 7.722 & 0.131 & 1,048 & 22 & 1,295 & 22 & 0.035 & 1.000 & 0.010 & - \\
\hline Protein & 6.566 & 0.069 & 6.729 & 0.073 & 1,523 & 16 & 1,486 & 16 & 0.074 & 0.100 & 1.000 & - \\
\hline Fat A & 5.764 & 0.053 & 5.590 & 0.050 & 1,735 & 16 & 1,789 & 16 & - & 0.080 & 0.055 & 1.000 \\
\hline \multicolumn{13}{|c|}{$\begin{array}{l}\text { Optimized Fourier transform mid-infrared center wavelengths } \\
\text { and bandwidths (i.e., minimized size of intercorrection factors) }\end{array}$} \\
\hline Fat B & 3.508 & 0.032 & 3.556 & 0.030 & 2,851 & 26 & 2,812 & 24 & 1.000 & -0.160 & -0.065 & - \\
\hline Lactose & 9.542 & 0.182 & 7.734 & 0.084 & 1,048 & 20 & 1,293 & 14 & 0.038 & 1.000 & 0.015 & - \\
\hline Protein & 6.489 & 0.085 & 6.707 & 0.054 & 1,541 & 20 & 1,491 & 12 & 0.065 & 0.050 & 1.000 & - \\
\hline Fat A & 5.721 & 0.052 & 5.583 & 0.050 & 1,748 & 16 & 1,791 & 16 & - & 0.030 & 0.025 & 1.000 \\
\hline
\end{tabular}

$\stackrel{2}{0} \mathrm{~A}$ dash (-) indicates not used. 

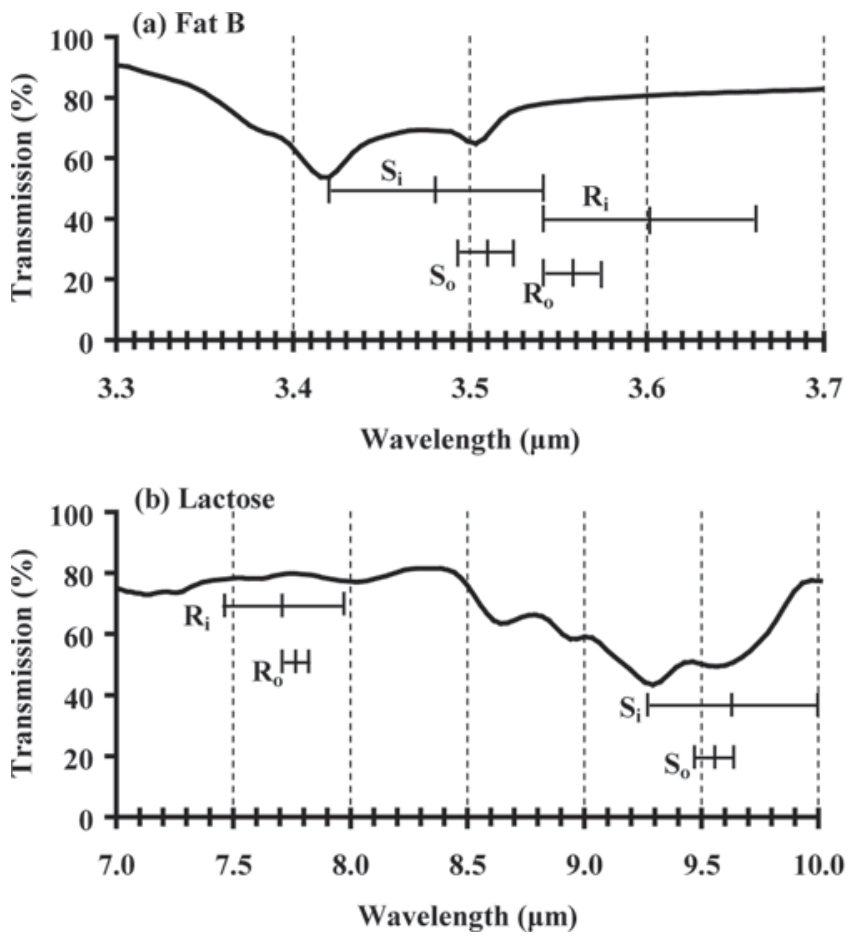

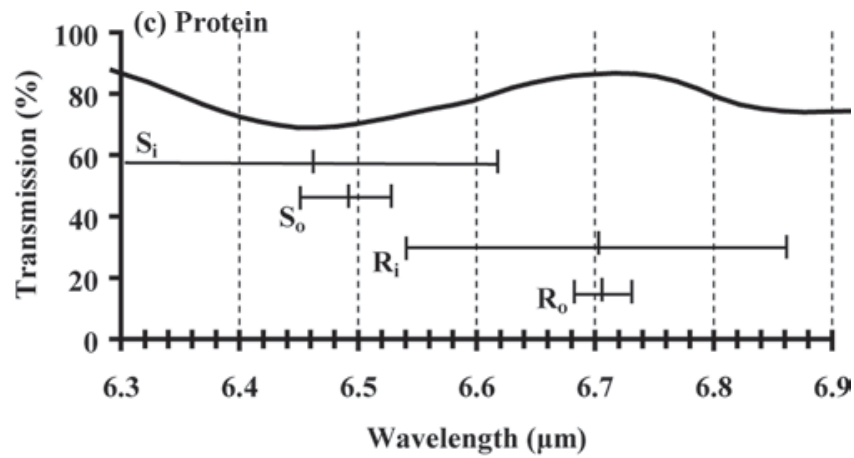

(d) Fat A

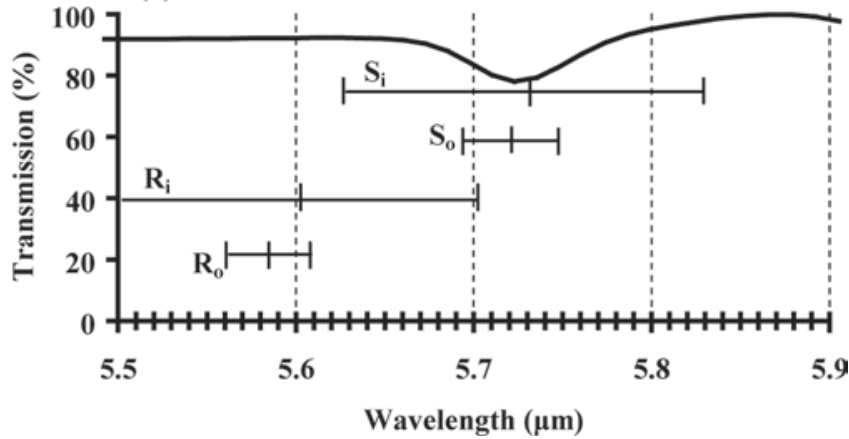

Figure 3. Mid-infrared transmission spectra of milk (with the water subtracted) from a LactoScope Fourier transform infrared instrument (Delta Instruments, Drachten, the Netherlands) expanded to show sample (S) and reference (R) mean center wavelengths and bandwidths for initial (i) optical and optimized virtual (o) filters: a) fat B (center wavelengths: $S_{i}=3.48 \mu \mathrm{m}, \mathrm{S}_{0}=3.508 \mu \mathrm{m}, \mathrm{R}_{\mathrm{i}}=3.60 \mu \mathrm{m}, \mathrm{R}_{\mathrm{o}}=3.556 \mu \mathrm{m}$ ); b) lactose (center wavelengths: $\left.\mathrm{S}_{\mathrm{i}}=9.61 \mu \mathrm{m}, \mathrm{S}_{\mathrm{o}}=9.542 \mu \mathrm{m}, \mathrm{R}_{\mathrm{i}}=7.70 \mu \mathrm{m}, \mathrm{R}_{\mathrm{o}}=7.734 \mu \mathrm{m}\right) ; \mathrm{c}$ ) protein (center wavelengths: $\mathrm{S}_{\mathrm{i}}=6.46 \mu \mathrm{m}, \mathrm{S}_{\mathrm{o}}=$ $6.489 \mu \mathrm{m}, \mathrm{R}_{\mathrm{i}}=6.70 \mu \mathrm{m}, \mathrm{R}_{\mathrm{o}}=6.707 \mu \mathrm{m}$ ); and d) fat A (center wavelengths: $\mathrm{S}_{\mathrm{i}}=5.73 \mu \mathrm{m}, \mathrm{S}_{\mathrm{o}}=5.721 \mu \mathrm{m}, \mathrm{R}_{\mathrm{i}}=5.60 \mu \mathrm{m}, \mathrm{R}_{\mathrm{o}}=5.583 \mu \mathrm{m}$ ).

filters (Figure 3d). The sample and reference center wavelengths for fat A were moved from the initial values of 5.73 and $5.60 \mu \mathrm{m}$ (Table 1 and Figure 3d) to optimized values of 5.721 and $5.583 \mu \mathrm{m}$ (Table 3 and Figure 3d), respectively, to move them farther from the water absorption peak. The optimized bandwidths and center wavelengths (Table 3 and Figure 3d) compared with the initial settings decreased the size of the lactose on the fat A intercorrection factor. Another benefit of moving away from the area of intense water absorption was reduced sensitivity of the fat A measurement to minor variations in sample temperature and improved repeatability (data not shown).

The optimized sample and reference center wavelengths and bandwidths for fat B, lactose, protein, and fat A were used as the virtual filters on the LactoScope FTIR instrument (Table 3) to determine the influence of changes in fatty acid chain length and unsaturation of triglycerides on light absorbance at sample and reference wavelengths and on MIR fat prediction of model milk emulsions in the next experiment.

\section{Influence of Fatty Acid Chain Length and Unsaturation of Milk Emulsions on MIR Analysis}

Particle Size and Fat Content of Emulsions. The stock C14:0, C16:0, C18:0, and C18:1 emulsions were analyzed for particle size distribution to ensure that the pilot scale homogenization during emulsion preparation was sufficient to produce a particle size distribution with a $\mathrm{d}(0.9)<1.7 \mu \mathrm{m}$ to avoid interference attributable to light scattering in the MIR milk analyzer (Smith et al., 1995). The particle size for each stock emulsion in all 3 replicates was $\mathrm{d}(0.9)<0.73 \mu \mathrm{m}$ (Table 4).

The fat contents (wt/wt) of the stock emulsions (Table 4) were determined by ether extraction and ranged from 1.93 to $2.14 \%$ fat. The stock emulsions were used to make a series of samples that differed in fatty acid chain length from 14.0 to 16.0 carbons and a series that differed in unsaturation from 0 to 1 double bond per fatty acid. The FFA contents of the stock emulsions were determined on the first replicate (pure triglyceride from the same lot was used in replicates 2 and 3) to determine the level of contamination by FFA in the triglyceride standards used to make the stock emulsions. The FFA contents for the stock emulsions (Table 4) were uniformly low and were consistent with values typical for milk (Kaylegian et al., 2007). Therefore, there were no significant differences in background FFA content of milk emulsions within the chain length or unsaturation series. To maintain a consistent fat concentration among solutions, the individual samples 
Table 4. Particle size, fat content, and FFA content of the stock emulsions

\begin{tabular}{|c|c|c|c|c|c|c|c|}
\hline Stock emulsion & \multicolumn{3}{|c|}{ Particle size $d(0.9), \mu \mathrm{m}$} & \multicolumn{3}{|c|}{ Fat content, $\%$} & $\begin{array}{c}\text { FFA, replicate } 1, \\
\mathrm{mEq} / \mathrm{kg} \\
\text { of } \mathrm{milk}\end{array}$ \\
\hline C14:0 & 0.52 & 0.55 & 0.57 & 1.965 & 1.984 & 2.059 & 0.050 \\
\hline C18:0 & 0.58 & 0.73 & 0.57 & 1.927 & 2.093 & 1.936 & 0.058 \\
\hline C18:1 & 0.51 & 0.53 & 0.55 & 1.949 & 1.943 & 2.015 & 0.048 \\
\hline
\end{tabular}

in the chain length and unsaturation series were formulated to a fat level of $1.90 \pm 0.01 \%$ by the addition of skim milk. The same batch of pasteurized skim milk was used for making the stock emulsions and for dilution so that the protein and lactose concentrations in the background were the same in all the samples.

Influence of Fatty Acid Chain Length on MIR Absorption at the Fat $B$ and Fat $A$ Wavelengths. Data for MIR light absorption at sample and reference wavelengths in Figures 4 through 7 were collected with the LactoScope FTIR instrument by using the optimized filter bandwidths and center wavelengths described in Table 3. A significant $(P \leq 0.01)$ increase in absorbance was detected at the sample center wavelength for fat B $(3.508 \mu \mathrm{m})$ as the fatty acid chain length increased (Figure 4a). This was expected because the principle that led to development of the fat B filter for use in MIR milk analysis (Biggs and McKenna, 1989) was the increase in $\mathrm{C}-\mathrm{H}$ stretch absorption with increasing fatty acid chain length. As the fatty acid chain length increased from 14.0 to 16.0 carbons, the absorbance at $3.508 \mu \mathrm{m}$ increased by 0.0035 units per fatty acid carbon (Figure 4a) for milk emulsions with constant unsaturation (i.e., fully saturated) and the same background (i.e., constant lactose and protein content). No change in light absorbance was detected at the fat $\mathrm{B}$ reference wavelength (Figure 4a).

A significant $(P \leq 0.01)$ decrease in absorbance was detected at the sample center wavelength for fat A $(5.721 \mu \mathrm{m})$ as the fatty acid chain length increased (Figure 4b). As the mean fatty acid chain length increased, the number of carbonyl groups as a percentage of the total weight of fat decreased. The general trends of increasing absorption at fat B and decreasing absorption at fat $\mathrm{A}$ as the mean fatty acid chain length (i.e., MW) changed have been reported previously (Mills and van de Voort, 1982; Biggs and McKenna, 1989), but have not been quantified. As the fatty acid chain length increased from 14.0 to 16.0 carbons, the absorbance at $5.721 \mu \mathrm{m}$ (fat A) decreased by -0.0035 units per fatty acid carbon (Figure $4 \mathrm{~b}$ ) for milk emulsions with a constant unsaturation (i.e., fully saturated) and the same background (i.e., a constant lactose and protein content). No significant $(P>0.05)$ changes in absor- bance at the fat A reference wavelength (Figure $4 \mathrm{~b}$ ) were detected.

Influence of Fatty Acid Unsaturation on MIR Absorption at the Fat $B$ and Fat $A$ Wavelengths. Significant $(P \leq 0.01)$ decreases in absorbance were detected at both the fat B sample and reference center wavelengths (3.508 and $3.556 \mu \mathrm{m}$, respectively) as the unsaturation of fatty acids increased (Figure 5a). The decrease in absorbance was due to the decrease in the number of $\mathrm{C}-\mathrm{H}$ groups as the mean unsaturation increased. In the milk emulsions, the absorption at the fat $B$ sample and reference wavelengths decreased by -0.0336 and -0.0031 units per carbon-carbon double bond, respectively, as unsaturation increased from 0.0 to 1.0 double bonds (Figure 5a). The change in absorbance at the fat B sample wavelength with a unit change in unsaturation (Figure 5a) was much larger, and in the opposite direction, compared with the change in absorbance at the fat B sample wavelength with a unit change in mean fatty acid chain length (Figure 4a).

An increase $(P \leq 0.01)$ in light absorbance for the fat A sample wavelength with increasing unsaturation was detected (Figure 5b). The absorbance at the fat A sample wavelength increased by 0.0041 units per double bond (Figure 5b). The MIR response to changes in unsaturation was much larger at the fat B sample wavelength (Figure 5a) than at the fat A sample wavelength, which was expected (Mills and van de Voort, 1982; Biggs and McKenna, 1989). No change $(P>$ 0.05) in absorbance at the fat A reference wavelength attributable to a change in fatty acid unsaturation was detected (Figure 5b).

Influence of Fatty Acid Chain Length and Unsaturation on the MIR Spectra. Full-spectrum data obtained during FT MIR analysis can be used in ways other than a virtual filter approach with fixed intercorrection factors. Classical least squares regression, inverse least squares regression, principal component regression, and partial least squares regression have been used (Luinge et al., 1993). If these multivariate statistical methods, using more data from the spectra than the fixed-filter approach, are expected to give better agreement between reference chemistry and the MIR prediction, then there must be additional informa- 

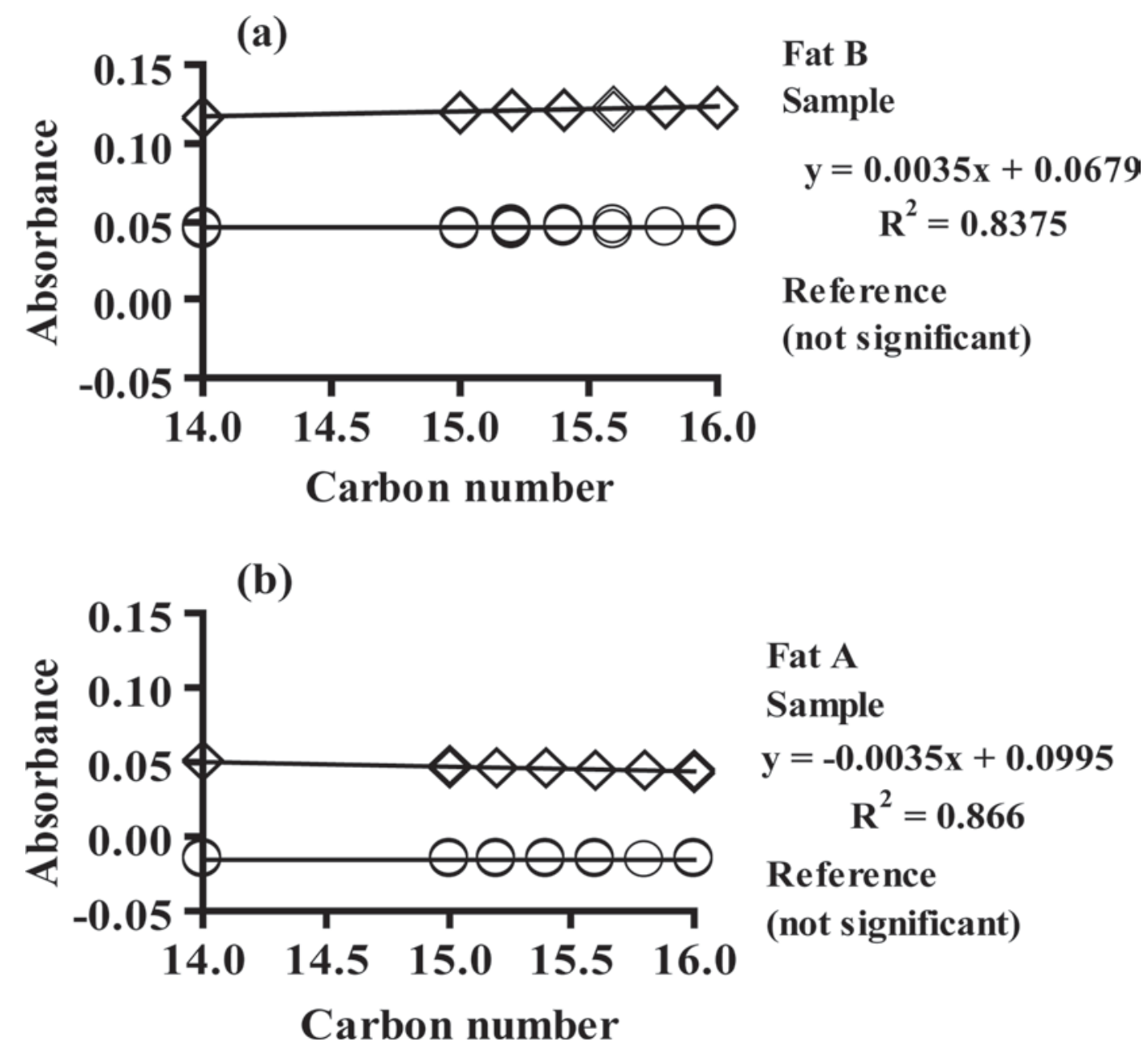

Figure 4. Mid-infrared absorbance of milk emulsions (3 replicates, 7 emulsions per replicate) with increasing fatty acid chain length (carbon number) measured with a LactoScope Fourier transform infrared instrument (Delta Instruments, Drachten, the Netherlands): a) fat B sample $(\diamond)=3.508 \mu \mathrm{m}$, and reference $(\bigcirc)=3.556 \mu \mathrm{m}$; b) fat A sample $(\diamond)=5.721 \mu \mathrm{m}$, and reference $(\bigcirc)=5.583 \mu \mathrm{m}$.

tion in the spectra that correlates with the variations (e.g., chain length and unsaturation) that cause errors in the fixed-filter approach. These variations in chain length and unsaturation and any other natural variations combined with the variation in the primary components in milk (i.e., fat, protein, and lactose) have to be adequately represented in the sample set of spectra used to develop the multivariate model.

The series of spectra for increasing chain length and unsaturation were sequentially compared with each other by subtracting the spectra for the first sample in the series from each subsequent sample and plotting the difference spectra as a function of increasing chain length and increasing unsaturation. Sequential changes in absorbance with increasing chain length and unsaturation were not detected at other than the classical wavelengths in the range of 3.3 to $10 \mu \mathrm{m}$. This would indicate that multivariate techniques could have a dif- ficult time compensating for variation in chain length or unsaturation beyond what has been done with the traditional fixed-filter approach. Luinge et al. (1993) used 4 multivariate statistical methods (i.e., classical least squares, inverse least squares, principal component, and partial least squares regression) and evaluated calibration and validation of an FT MIR milk analyzer using a population of 55 raw producer milk samples. Based on comparison of the SDD between instrument prediction using the 4 multivariate statistical methods and the fixed-filter approach, they concluded that there were no significant $(P>0.99)$ differences between these approaches. Similar conclusions were made by van de Voort et al. (1992). Spectral methods of calibration with the FT MIR milk analyzer may be more useful for analysis of manufactured dairy products (e.g., ice cream mixes), for which the range of variation in milk component concentrations is small but for which other 
(a)

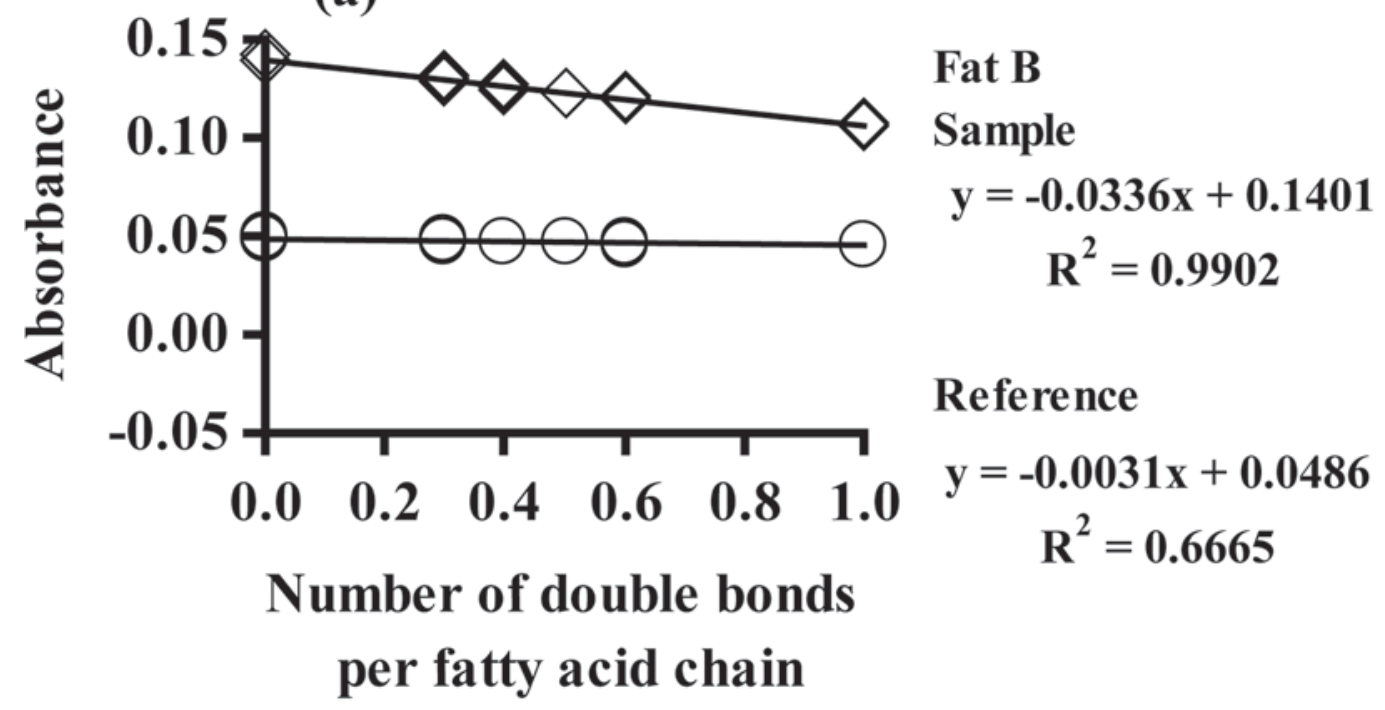

(b)

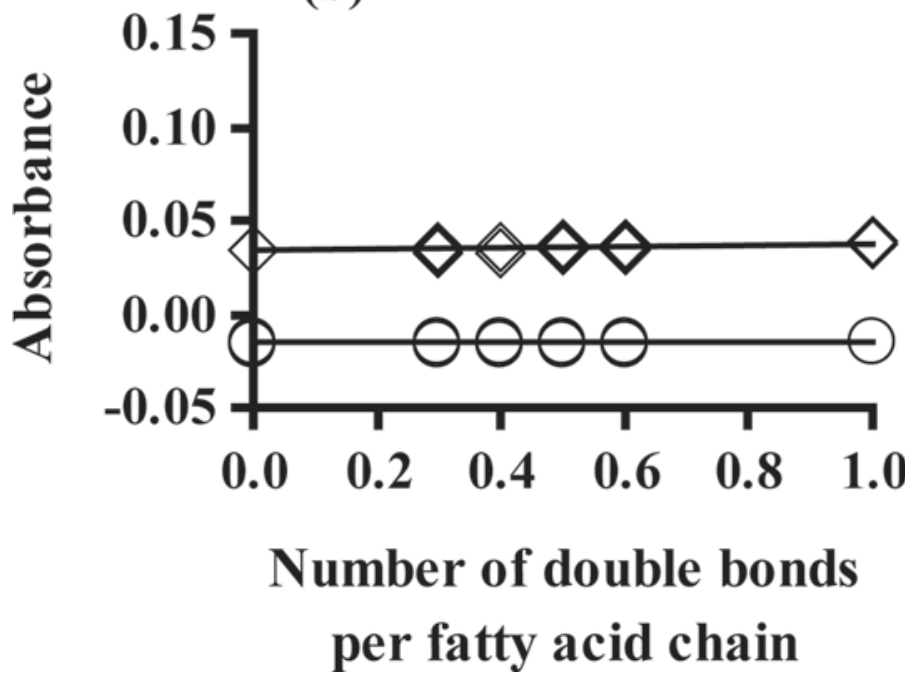

Fat A

Sample

$y=0.0041 x+0.0336$

$R^{2}=0.5013$

Reference

(not significant)

Figure 5. Mid-infrared absorbance of model milk emulsions (3 replicates, 6 emulsions per replicate) with increasing unsaturation (double bonds per fatty acid chain) measured with a LactoScope Fourier transform infrared instrument (Delta Instruments, Drachten, the Netherlands): a) fat B sample $(\diamond)=3.508 \mu \mathrm{m}$, and reference $(\bigcirc)=3.556 \mu \mathrm{m}$; b) fat A sample $(\diamond)=5.721 \mu \mathrm{m}$, and reference $(\bigcirc)=5.583 \mu \mathrm{m}$.

added ingredients absorb light in the areas that interfere with the measurement of the main components.

Influence of Fatty Acid Chain Length on MIR Predicted Fat Content. The prediction of fat content of milk using MIR analysis is influenced not only by the light absorbance of milk fat at the selected wavelength (fat B or fat A), but also by protein, lactose, and water, and by changes in the secondary slope and intercept (Lynch et al., 2006). In the milk emulsions used in this study, the background protein and lactose content and total fat content were kept constant so that relative changes within each series of milk emulsions in the
MIR-predicted fat content were due solely to changes in the fatty acid chain length or unsaturation. The MIR prediction was determined using either $100 \%$ fat B or $100 \%$ fat A on both the LactoScope FTIR instrument using virtual filters set to the optimized center wavelength and bandwidth settings (Table 3 ) and on the MilkoScan 605 instrument with optical filters (Table $1)$.

Increasing the mean fatty acid chain length increased $(P<0.01)$ the difference (i.e., MIR minus reference) between MIR prediction of fat and ether extraction reference chemistry for fat B by $0.0429 \%$ fat per unit 
increase in carbon number per $1 \%$ fat content on the LactoScope FTIR instrument (Figure 6a). A similar, but slightly smaller, increase $(0.0319 \%$ fat $)$ in the difference $(P<0.01)$ between MIR prediction of fat and ether extraction reference chemistry was observed with the MilkoScan 605 instrument (data not shown). Therefore, if fat B were used to predict the fat content of 2 milk samples that both contained $3.6 \%$ fat (ether extraction) and the same unsaturation but differed from each other by 1 carbon in mean fatty acid chain length, the difference in predicted fat content would be 0.15 and $0.11 \%$ for the Lactoscope FTIR instrument and the MilkScan 605 instrument, respectively. The milk having the longer fatty acid chain length would give a higher prediction.

Increasing the mean fatty acid chain length decreased $(P<0.01)$ the difference between the MIR prediction and ether extraction reference chemistry for fat A by $-0.0566 \%$ fat per unit increase in carbon number per $1 \%$ fat content on the LactoScope FTIR instrument (Figure 6b). A similar, but slightly larger, decrease $(-0.0604 \%)$ in the difference $(P<0.01)$ between MIR prediction of fat and ether extraction reference chemistry was observed on the MilkoScan 605 instrument (data not shown). Therefore, if fat A was used to predict the fat content of 2 milk samples with $3.6 \%$ fat (ether extraction) and the same unsaturation but that differed from each by 1 carbon in mean fatty acid chain length, the difference in predicted fat content would be -0.20 and $-0.22 \%$ for the Lactoscope FTIR and the MilkScan 605 instrument, respectively. Thus, differences in chain length among milks caused the fat $\mathrm{A}$ and fat $\mathrm{B}$ readings to deviate in opposite directions.

The MilkoScan 605 and LactoScope FTIR instruments used in this study were calibrated with a modified milk set (Kaylegian et al., 2006) that had a mean fatty acid chain length of approximately 14.50 carbons and a mean unsaturation of approximately 0.327 double bonds per fatty acid. The milk emulsions, which varied only in fatty acid chain length, ranged from 14.0 to 16.0 carbons and encompassed the mean fatty acid chain length of the calibration milk, but these milk emulsions had an unsaturation of 0.0 double bonds. Consequently, the difference between the MIR-predicted value and reference chemistry was always above the $0.0 \%$ fat per $1 \%$ fat on the y-axis as fatty acid chain length increased for fat B (Figure 6a) because of the difference in average fatty acid chain length between the modified milk samples and the model milk emulsions.

Influence of Unsaturation on MIR-Predicted Fat Content. Increasing unsaturation of fatty acids had a large effect $(P<0.01)$ on the difference (i.e., MIR minus reference) between the MIR prediction and ether extraction reference chemistry for fat $\mathrm{B}$. The percentage of fat B changed by $-0.4021 \%$ fat per unit increase in double bonds per $1 \%$ fat content on the LactoScope FTIR instrument (Figure 7a). A similar decrease $(-0.3533 \%$ fat $)$ with increasing unsaturation was observed on the MilkoScan 605 instrument (data not shown). If fat $\mathrm{B}$ were used to predict fat content of 2 milk samples with $3.6 \%$ fat (ether extraction) and the same mean fatty acid chain length but the 2 milk samples differed in unsaturation by 0.15 double bonds per fatty acid, the difference in predicted fat content between the 2 samples would be -0.22 and $-0.19 \%$ for the LactoScope FTIR and the MilkoScan 605 instruments, respectively. Thus, at the fat B wavelength, simultaneous changes in chain length and unsaturation would influence the MIR prediction in opposite directions, so on individual unknown milks the operator would observe the net effect of the two.

Increasing unsaturation of fatty acids had a small $(P$ $<0.01$ ) effect on the fat A MIR prediction. The difference between the MIR prediction and ether extraction reference chemistry for fat A increased by $0.0291 \%$ fat per unit increase in double bonds per $1 \%$ fat on the LactoScope FTIR instrument (Figure 7b). A smaller increase $(0.004 \%$ fat) with increasing unsaturation was observed on the MilkoScan 605 instrument (data not shown). If fat A were used to predict fat content of 2 milk samples with $3.6 \%$ fat (ether extraction) and the same mean fatty acid chain length but that differed in unsaturation by 0.15 double bonds per fatty acid, the difference in predicted fat content between the 2 samples would be 0.02 and $0.00 \%$ for the LactoScope FTIR and the MilkoScan 605 instruments, respectively. From a practical point of view, variation in fatty acid unsaturation would have little impact on the fat A MIR reading.

The MilkoScan 605 and LactoScope FTIR instruments used in this study were calibrated with a modified milk set (Kaylegian et al., 2006) that had a mean fatty acid chain length of approximately 14.50 carbons and a mean unsaturation of approximately 0.327 double bonds. The milk emulsions, which varied only in unsaturation, ranged from 0 to 1 double bonds per fatty acid and encompassed the mean number of double bonds of the calibration milk, but the milk emulsions had an average chain length of 18 carbons. Consequently, the difference between the MIR-predicted value and reference chemistry was always above the $0.0 \%$ fat per $1 \%$ fat mark as unsaturation increased for fat B (Figure 7a) and was below the $0.0 \%$ fat for $1 \%$ fat mark for fat A (Figure 7b).

Chain Length and Unsaturation in Routine Calibration Samples. Variations in fatty acid chain length and unsaturation from sample to sample within a set of producer milk calibration sets used to adjust 

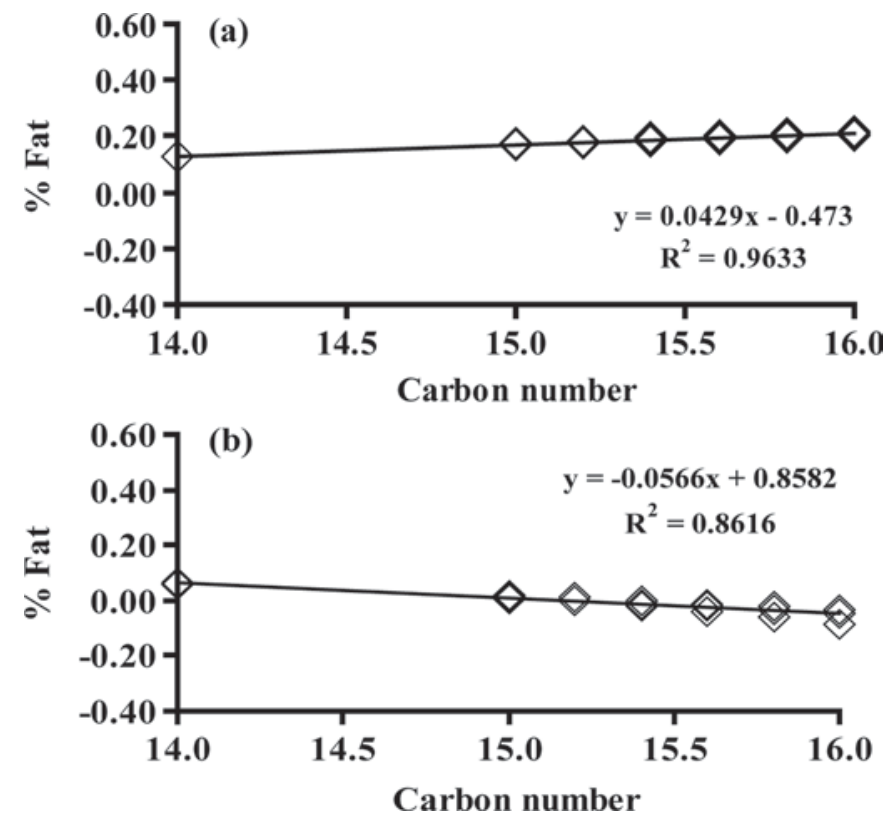

Figure 6. Difference between corrected mid-infrared fat reading (LactoScope Fourier transform infrared instrument, Delta Instruments, Drachten, the Netherlands) minus reference chemistry, per $1 \%$ fat, of model milk emulsions (3 replicates, 7 emulsions per replicate) as fatty acid chain length (carbon number) increased: a) fat B; b) fat A.

the secondary slope and intercept will cause deviations from ether extraction reference values that cannot be correctly compensated for by either the fat B or fat A wavelengths when using the fixed-filter approach. If a sample with an extreme value for chain length or unsaturation happened to be a high-leverage sample (Kaylegian et al., 2006), then this would create errors in secondary slope and intercept adjustment. This should be avoided in making sets of calibration samples, but is almost impossible to avoid when using calibration samples made from different individual farm milks. In a modified milk calibration set, the fatty acid chain length and unsaturation do not vary from sample to sample within the calibration set (Kaylegian et al., 2006). The MilkoScan 605 and LactoScope FTIR instruments used in this study were calibrated with modified milks that had a mean fatty chain length of 14.50 carbons and a mean unsaturation of 0.327 double bonds. The population of producer milks to be tested for payment would have an average chain length and unsaturation. It would be best if the mean fatty acid chain length and unsaturation in the modified milk calibration samples were similar to the mean fatty acid chain length and unsaturation of the producer milk samples. More work with better control of sample selection and reference chemistry analysis is needed to determine how well multivariate models can compensate for variation in fatty acid chain length and unsaturation.

Chain Length and Unsaturation in Producer Milk. Clearly, variation in fatty acid composition of milk fat from farm to farm influences the accuracy of MIR fat prediction in payment testing. Infrared milk testing has weaknesses in this area, and a more thorough understanding of MIR spectra when fatty acid composition varies may allow the development of improved calibration approaches. Variation in feeding practices for dairy cows in different herds and regions of the country is the primary cause of variation in the fatty acid composition of milk from farm to farm. In the last $20 \mathrm{yr}$ in the United States, larger herd sizes and more aggressive nutrition management, using dairy cattle rations with higher fat content and protected fats, to maximize milk production may have changed the average fatty acid composition and the farm-tofarm variation in fatty acid composition of milk fat. More information is needed on the current status of farm-to-farm variation in milk fatty acid composition as it relates to MIR milk analysis.

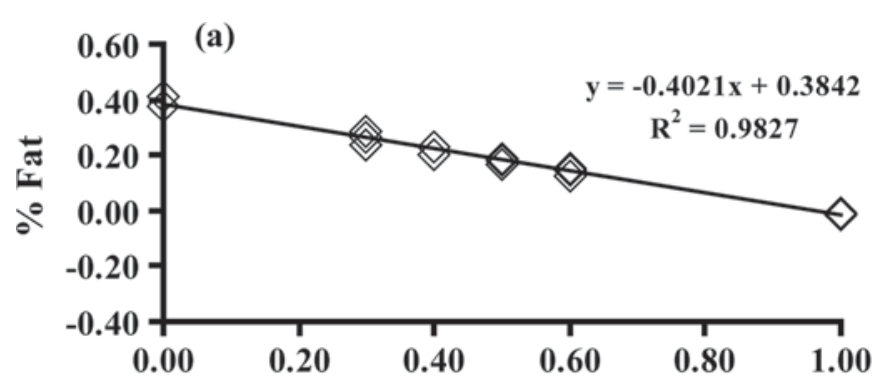

Number of double bonds per fatty acid chain

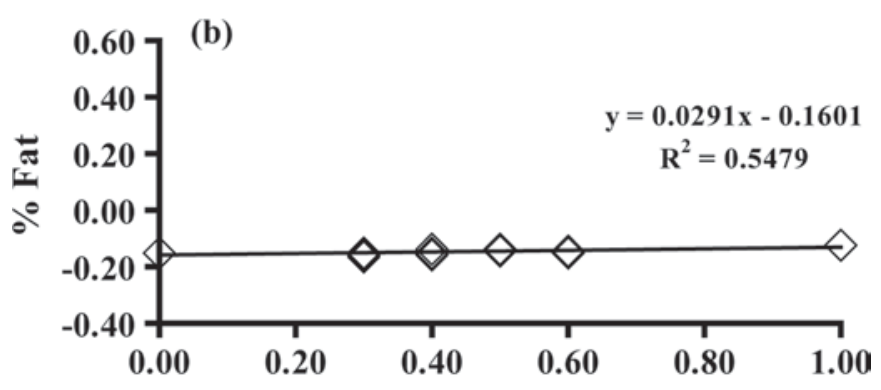

Number of double bonds per fatty acid chain

Figure 7. Difference between corrected mid-infrared fat reading (LactoScope Fourier transform infrared instrument, Delta Instruments, Drachten, the Netherlands) minus reference chemistry, per $1 \%$ fat, of model milk emulsions (3 replicates, 6 emulsions per replicate) as unsaturation (double bonds per fatty acid chain) increased: (a) fat B; (b) fat $\mathrm{A}$. 


\section{CONCLUSIONS}

Specifications for virtual filters to be used in the fixed-filter approach to calibration with an FT MIR milk analyzer that produced minimum-sized intercorrection factors were determined. They are as follows: fat B sample, $3.508 \mu \mathrm{m}\left(2,851 \mathrm{~cm}^{-1}\right)$ with a bandwidth of $0.032 \mu \mathrm{m}\left(26 \mathrm{~cm}^{-1}\right)$, and fat B reference, $3.556 \mu \mathrm{m}$ $\left(2,812 \mathrm{~cm}^{-1}\right)$ with a bandwidth of $0.030 \mu \mathrm{m}\left(24 \mathrm{~cm}^{-1}\right)$; lactose sample, $9.542 \mu \mathrm{m}\left(1,048 \mathrm{~cm}^{-1}\right)$ with a bandwidth of $0.182 \mu \mathrm{m}\left(20 \mathrm{~cm}^{-1}\right)$, and lactose reference, $7.734 \mu \mathrm{m}\left(1,293 \mathrm{~cm}^{-1}\right)$ with a bandwidth of $0.084 \mu \mathrm{m}$ $\left(14 \mathrm{~cm}^{-1}\right)$; protein sample, $6.489 \mu \mathrm{m}\left(1,541 \mathrm{~cm}^{-1}\right)$ with a bandwidth of $0.085 \mu \mathrm{m}\left(20 \mathrm{~cm}^{-1}\right)$, and protein reference $6.707 \mu \mathrm{m}\left(1,491 \mathrm{~cm}^{-1}\right)$ with a bandwidth of 0.054 $\mu \mathrm{m}\left(12 \mathrm{~cm}^{-1}\right)$; fat A sample, $5.721 \mu \mathrm{m}\left(1,748 \mathrm{~cm}^{-1}\right)$ with a bandwidth of $0.052 \mu \mathrm{m}\left(16 \mathrm{~cm}^{-1}\right)$, and fat A reference, $5.583 \mu \mathrm{m}\left(1,791 \mathrm{~cm}^{-1}\right)$ with a bandwidth of $0.050 \mu \mathrm{m}\left(16 \mathrm{~cm}^{-1}\right)$. These center wavelengths and bandwidths should be transferable from one FTIR milk analyzer to another if the wavelength calibrations of the interferometers are equivalent. The bandwidth and the proximity of the wavelengths to areas of intense water absorption had the largest effects on the size of intercorrection factors. The use of narrow bandwidths allowed movement of the center wavelengths away from areas of intense water absorption and reduced the influence of background variation in water concentration and variation in concentrations of milk components on each other.

There was a significant increase in light absorbance at the fat $\mathrm{B}$ sample wavelengths and a decrease at the fat A sample wavelengths with increasing fatty acid chain length, and no change at either reference wavelength. With increasing unsaturation, there was a significant decrease in light absorbance at both the fat $\mathrm{B}$ and fat $\mathrm{A}$ sample wavelengths, whereas absorbance at the fat $\mathrm{B}$ reference decreased slightly and the fat A reference did not change. Increasing the mean fatty acid chain length (i.e., MIR minus reference) between MIR prediction of fat and ether extraction reference chemistry for fat B to be higher by $0.0429 \%$ and fat A to be lower by $-0.0566 \%$ fat per unit increase in carbon number per $1 \%$ fat content in a milk sample on the LactoScope FTIR instrument using the optimized virtual filter wavelengths. As the mean fatty acid unsaturation increased the difference (i.e., MIR minus reference) between MIR prediction of fat and ether extraction reference chemistry for fat B was lower by $-0.4021 \%$ and fat A was higher by $0.0291 \%$ fat per unit increase in double bonds per $1 \%$ fat content in a milk sample using the optimized virtual filter wavelengths. Similar results were obtained on a second MIR milk analyzer with optical filters.

\section{ACKNOWLEDGMENTS}

The authors thank Cornell University staff members Maureen Chapman, Debbie Dwyer, Jessica Mallozzi, and Karen Wojciechowski for their technical assistance in sample preparation and analysis. The authors thank the Test Procedures Committee of the USDA, Dairy Programs, Federal Milk Markets for their financial support of this research.

\section{REFERENCES}

Agnet, Y. 1998. Fourier transform infrared spectrometry. A new concept for milk and milk product analysis. Bull. Int. Dairy Fed. 332:58-68.

Alpert, N. L., W. E. Keiser, and H. A. Szymanski. 1970. Instruments. Pages 9-64 in Theory and Practice of Infrared Spectroscopy. Plenum Press, New York, NY.

AOAC. 2000. Official Methods of Analysis. AOAC Int., Gaithersburg, MD.

Barbano, D. M., and J. W. Sherbon. 1980. Polyunsaturated protected lipid feeding: Effect on triglyceride molecular weight distribution. J. Dairy Sci. 63:731-740.

Biggs, D. A., G. Johnsson, and L.-O. Sjaunja. 1987. Analysis of fat, protein, lactose and total solids by infra-red absorption. Pages 21-30 in Monograph on Rapid Indirect Methods for Measurement of the Major Components of Milk. Bull. Int. Dairy Fed. No. 208. Int. Dairy Fed., Brussels, Belgium.

Biggs, D. A., and D. McKenna. 1989. Alternative methods for infrared analysis of fat in milk: Interlaboratory study. J. AOAC 72:724734.

Dunkley, W. L., A. A. Franke, and L. M. Smith. 1977. Determining fat, protein, and lactose in milk from cows fed formaldehyde protected sunflower-soybean supplement. J. Dairy Sci. 60:45-52.

Foss Electric. 2002. FT120 Type 71200 Manual. Foss Electric, Hillerød, Denmark.

Franke, A. A., W. L. Dunkley, and N. E. Smith. 1977. Influence of feeding protected tallow on accuracy of analysis by infrared milk analyzer. J. Dairy Sci. 60:1870-1874.

Franke, A. A., W. L. Dunkley, and N. E. Smith. 1981. Influence of dairy rations with whole cottonseed or extruded soybeans on accuracy of analysis for milk components. J. Dairy Sci. 64:2185-2191.

Goulden, J. D. S. 1964. Analysis of milk by infra-red absorption. J. Dairy Res. 31:273-284.

Kaylegian, K. E., G. E. Houghton, J. M. Lynch, J. R. Fleming, and D. M. Barbano. 2006. Calibration of infrared milk analyzers: Modified milk versus producer milk. J. Dairy Sci. 89:2817-2832.

Kaylegian, K. E., J. M. Lynch, J. R. Fleming, and D. M. Barbano. 2007. Lipolysis and proteolysis of modified and producer milk used for calibration of mid-infrared milk analyzers. J. Dairy Sci. 90:602-615.

Luginbühl, W., and H. Eyer. 1992. FT-IR spectrometry-A promising method for dairy research and analysis. Lebensm. Wiss. Technol. 25:316-320.

Luinge, H. J., E. Hop, E. T. G. Lutz, J. A. van Hemert, and E. A. M. de Jong. 1993. Determination of the fat, protein and lactose content of milk using Fourier transform infrared spectrometry. Anal. Chim. Acta 284:419-433.

Lynch, J. M., D. M. Barbano, M. Schweisthal, and J. R. Fleming. 2006. Precalibration evaluation procedures for mid-infrared milk analyzers. J. Dairy Sci. 89:2761-2774.

Lynch, J. M., A. L. Lock, D. A. Dwyer, R. Noorbakhsh, D. M. Barbano, and D. E. Bauman. 2005. Flavor and stability of pasteurized milk with elevated levels of conjugated linoleic acid and vaccenic acid. J. Dairy Sci. 88:489-498.

Ma, Y., D. M. Barbano, and M. Santos. 2003. Effect of $\mathrm{CO}_{2}$ addition to raw milk on proteolysis and lipolysis at $4^{\circ} \mathrm{C}$. J. Dairy Sci. $86: 1616-1631$. 
Mills, B. L., and F. R. van de Voort. 1982. Evaluation of CH stretch measurement for estimation of fat in aqueous fat emulsions using infrared spectroscopy. J. AOAC 65:1357-1361.

Silverstein, R. M., and G. C. Bassler. 1967. Spectrometric Identification of Organic Compounds. John Wiley and Sons Inc., New York, NY.

Sjaunja, L.-O. 1984a. Studies on milk analyses of individual cow milk samples. I. Infrared spectrophotometry for analysis of fat, protein and lactose in milk. Acta Agric. Scand. 34:249-259.

Sjaunja, L.-O. 1984b. Studies on milk analyses of individual cow milk samples. II. Factors affecting milk analyses by infrared technique under laboratory conditions. Acta Agric. Scand. 34:260-272.

Smith, E. B., D. M. Barbano, and J. M. Lynch. 1995. Infrared analysis of milk: Effect of homogenizer and optical filter selection on apparent homogenization efficiency and repeatability. J. AOAC Int. $78: 1225-1233$

Stegeman, G. A., R. J. Baer, D. J. Schingoethe, and D. P. Casper. 1991. Influence of milk fat higher in unsaturated fatty acids on the accuracy of milk fat analyses by the mid-infrared spectroscopic method. J. Food Prot. 54:890-893.

Stewart, J. E. 1970. Optical filters. Page 164-174 in Infrared Spectroscopy Experimental Methods and Techniques. Marcel Dekker Inc., New York, NY.

van de Voort, F. R., J. Sedman, G. Emo, and A. A. Ismail. 1992. Assessment of Fourier transform infrared analysis of milk. J. AOAC Int. 75:780-785. 